\title{
Characteristics of the corpus callosum in chronic schizophrenia treated with clozapine or risperidone and those never- treated
}

Bo Tao ${ }^{1,2 \dagger}$, Yuan Xiao ${ }^{1,2+}$, Hengyi Cao ${ }^{3,4}$, Wenjing Zhang ${ }^{1,2}$, Chengmin Yang ${ }^{1,2}$, Rebekka Lencer ${ }^{5}$, Qiyong Gong ${ }^{1,2}$ and Su Lui ${ }^{1,2^{*}}$

\begin{abstract}
Background: The corpus callosum (CC) deficits have been well documented in chronic schizophrenia. However, the long-term impacts of antipsychotic monotherapies on callosal anatomy remain unclear. This cross-sectional study sought to explore micro- and macro-structural characteristics of the CC in never-treated patients and those with long-term mono-antipsychotic treatment.

Methods: The study included 23 clozapine-treated schizophrenia patients (CT-SCZ), 19 risperidone-treated schizophrenia patients (RT-SCZ), 23 never-treated schizophrenia patients (NT-SCZ), and 35 healthy controls (HCs). High resolution structural images and diffusion tensor imaging (DTI) data for each participant were obtained via a 3.0 T MR scanner. FreeSurfer was used to examine the volumes and fractional anisotropy (FA) values of the CC for each participant.

Results: There were significant deficits in the total and sub-regional CC volume and white matter integrity in NTSCZ in comparison with healthy subjects. Compared with NT-SCZ, both CT-SCZ and RT-SCZ showed significantly increased FA values in the anterior CC region, while only RT-SCZ showed significantly increased volume in the midanterior CC region. Moreover, the volume of the mid-anterior CC region was significantly smaller in CT-SCZ compared to HCs. No correlations of clinical symptoms with callosal metrics were observed in schizophrenia patients.

Conclusions: Our findings provide insight into micro- and macro-structural characteristics of the CC in chronic schizophrenia patients with or without antipsychotics. These results suggest that the pathology itself is responsible for cerebral abnormalities in schizophrenia and that chronic exposure to antipsychotics may have an impact on white matter structure of schizophrenia patients, especially in those with risperidone treatment.
\end{abstract}

\footnotetext{
* Correspondence: lusuwcums@hotmail.com

${ }^{\dagger}$ Bo Tao and Yuan Xiao contributed equally to this work.

'Huaxi MR Research Center (HMRRC), Functional and Molecular Imaging Key

Laboratory of Sichuan Province, Department of Radiology, West China

Hospital, Sichuan University, 37 Guo Xuexiang, Chengdu 610041, China

${ }^{2}$ Psychoradiology Research Unit of the Chinese Academy of Medical

Sciences, West China Hospital of Sichuan University, Chengdu, China

Full list of author information is available at the end of the article
}

(c) The Author(s). 2021 Open Access This article is licensed under a Creative Commons Attribution 4.0 International License, which permits use, sharing, adaptation, distribution and reproduction in any medium or format, as long as you give appropriate credit to the original author(s) and the source, provide a link to the Creative Commons licence, and indicate if changes were made. The images or other third party material in this article are included in the article's Creative Commons licence, unless indicated otherwise in a credit line to the material. If material is not included in the article's Creative Commons licence and your intended use is not permitted by statutory regulation or exceeds the permitted use, you will need to obtain permission directly from the copyright holder. To view a copy of this licence, visit http://creativecommons.org/licenses/by/4.0/ The Creative Commons Public Domain Dedication waiver (http://creativecommons.org/publicdomain/zero/1.0/) applies to the data made available in this article, unless otherwise stated in a credit line to the data. 
Keywords: corpus callosum (CC), Magnetic resonance imaging (MRI), Diffusion tensor imaging (DTI), Fractional anisotropy (FA), Clozapine, Risperidone

\section{Background}

The corpus callosum (CC) is the largest commissural fiber in human brain and implicated in the etiopathology of schizophrenia [1-4]. However, little is known regarding the effects of antipsychotic medications on callosal anatomy in schizophrenia patients over long-term treatment $[5,6]$. Compared with healthy controls $(\mathrm{HCs})$, a recent study found increased volume of the posterior region of the $\mathrm{CC}$ in patients with long-term exposure to antipsychotic medications [5]. Moreover, patients with poor outcome after treatment had more pronounced reduction in CC size compared to good-outcome patients and HCs [6]. Notably, neither of these studies included long-term drug-naive patients as a comparison group, complicating the interpretation of the findings as whether they reflect effects of neuropathology or medication remains unclear.

Prior studies have demonstrated that the choice of antipsychotics may display different impacts on white matter structure in schizophrenia in terms of their different pharmacological mechanisms [7, 8]. Clozapine and risperidone, both of which are atypical antipsychotic medications, have been widely prescribed in clinical practice, but their pharmacological mechanisms are not exactly the same. Clozapine is the only antipsychotic medication approved for treatment-resistant schizophrenia in most countries [9]. It has a high affinity to dopamine $\mathrm{D} 4$ receptors and other receptors such as 5HT2A, 5HT1C, adrenergic receptors [10]. Risperidone is another atypical antipsychotic that is antagonistic to $5 \mathrm{HT} 2$ and dopamine D2 receptors [10]. In contrast, clozapine has a low affinity to dopamine D2 receptors [10]. In addition, our previous study on chronic schizophrenia showed less alterations in white matter structural networks in risperidonetreated patients compared with clozapine-treated or nevertreated patients [11]. However, few studies have explored the effects of long-term monotherapy with clozapine or risperidone on callosal structure in chronic schizophrenia.

In the present study, we combined structural magnetic resonance imaging (MRI) and diffusion tensor imaging (DTI) to examine the impacts of long-term clozapine and risperidone therapies on the micro- and macrostructures [fractional anisotropy (FA) \& volume respectively] of the $\mathrm{CC}$. According to our previous findings $[11,12]$, we hypothesized that antipsychotictreated schizophrenia patients would show larger volumes and/or increased FA values of the CC compared with never-treated patients, especially in those with long-term risperidone monotherapy.

\section{Methods \\ Participants}

The study was a cross-sectional design and recruited fortytwo chronic schizophrenia patients with long-term monoantipsychotic treatments, including 23 clozapine-treated schizophrenia patients (CT-SCZ) and 19 risperidone-treated schizophrenia patients (RT-SCZ), 23 never-treated chronic schizophrenia patients, and 35 HCs. Clinical diagnoses of schizophrenia were made by an experienced psychiatrist based on the Structured Clinical Interview for DSM-IV Axis I Disorders (SCID). The Nottingham Onset Schedule was conducted to evaluate illness onset and duration using information provided by patients, family members and available medical records [13]. The Positive and Negative Symptom Scale (PANSS) was used to estimate the severity of clinical symptoms of the patients [14].

Antipsychotic-treated patients were recruited from the local psychiatric clinic. All participants had received either clozapine or risperidone monotherapy consistently for over five years before entry into the study based on intact medical records. Never-treated schizophrenia patients (NT-SCZ) were recruited from a mental health screening program designed to provide psychiatric care to individuals with serious but untreated mental illness in rural areas around the Chengdu City of China. They did not receive any antipsychotic medications due to many factors, including family stigma, the lack of understanding of the severity of mental illness, and poor socioeconomic conditions.

HCs were recruited from the same community via poster advertisements. The non-patient edition of the SCID was used to ensure lifetime absence of psychotic, anxiety and mood disorders. Individuals with a known family history of major psychiatric illness in their first or second-degree relatives were excluded. All participants were right-handed and met the following inclusion criteria: 1) no history of substance abuse or dependence, 2) no history of significant systemic illness, head injury or neurologic illness, and 3) no contraindication to MR scanning.

The study methods were performed in accordance with the relevant guidelines and regulations. Ethical approval for this study was approved by the research ethics committee of West China Hospital of Sichuan University. All participants provided written informed consent for study procedures, and informed consent for schizophrenia patients was obtained from their parents or legal guardians. 


\section{MR image acquisition}

MRI examination of each subject was performed via a 3.0 T GE Signa EXCITE scanner (General Electric, Miwaukee, Wisconsin) with 8-channel phase array head coil. DTI images were obtained using a bipolar diffusion single-shot echo planar imaging sequence. Each DTI dataset included 15 images of non-collinear directions $\left(b=1000 \mathrm{~s} / \mathrm{mm}^{2}\right)$ with a reference image without diffusion weighting $(b=0)$. The acquisition parameters were as follows: $\mathrm{TR}=10,000 \mathrm{~ms}, \mathrm{TE}=70 \mathrm{~ms}$, flip angle $=90^{\circ}$, field of view $=24 \times 24 \mathrm{~cm}^{2}$, matrix size $=128 \times 128$, number of axial slice $=50$; and slice thickness $=3 \mathrm{~mm}$ (no gap). High resolution T1-weighted images for registration were obtained using a three-dimensional spoiled gradient (SPGR) sequence. The acquisition parameters were as follows: $\mathrm{TR}=8.5 \mathrm{~ms}, \mathrm{TE}=3.4 \mathrm{~ms}, \mathrm{TI}=400 \mathrm{~ms}$, flip angle $=12^{\circ}$, field of view $=24 \times 24 \mathrm{~cm}^{2}$, matrix size $=$ $256 \times 256 \times 128$, number of axial slice $=156$; and slice thickness $=1 \mathrm{~mm}$ (no gap).

\section{Imaging preprocessing and corpus callosum measurements}

FreeSurfer was used to preprocess imaging data, and to automatically identify and segment $\mathrm{CC}$ for each participant, which could reduce random errors, rater errors and inter-participant variability of manual editing [12]. The preprocessing pipeline of imaging data was displayed carefully in Fig. 1. Firstly, we conducted automated volumetric segmentation and cortical surface reconstruction of each high resolution $\mathrm{T} 1$-weighted data using the standard "recon_all" processing stream, as described carefully in other studies $[15,16]$. Then, volumetric segmentation and cortical surface reconstruction of each participant were examined carefully in a multiple view to identify whether there were too much or not enough removed regions. Next, the "dt_recon" command was used to preprocess diffusion-weighted images based on individual anatomical data derived from the "recon_all" procedure. It was performed via an orderly process that included eddy current and motion correction employing FSL's eddy_ correct, tensor construction and intra-subject registrations in native space. This yielded individual FA map, b0 image and other relevant maps. After visually checking the registration, we resampled individual white matter parcellation volume (wmparc.mgz) in its' diffusion space (b0 image) using the "mri_vol2vol" command, outputting a new segmentation volume named "wmparc2diff.mgz". Lastly, the "wmparc2diff.mgz" volume of each subject was applied to the corresponding FA map to analyze white matter integrity of a special brain region.

The CC of each subject was automatically divided into five components of equal length along the primary eigen direction using FreeSurfer, corresponding to its functional subdivisions, namely: anterior, mid-anterior, central, mid-posterior and posterior portions (Fig. 2) [17]. Total and subregional volumes of the $\mathrm{CC}$ were extracted via FreeSurfer. It was related with the lateral extent where white matter tracts that run horizontally from the mid-sagittal plane of the CC change direction bilaterally [17]. Moreover, FA values of five CC subregions were extracted according to the boundary defined by the $\mathrm{CC}$ volume segmentation.

\section{Total intracranial volume (TIV)}

We extracted total intracranial volume (TIV) $\left(\mathrm{mm}^{3}\right)$ of each participant in individual native space using FreeSurfer [18].

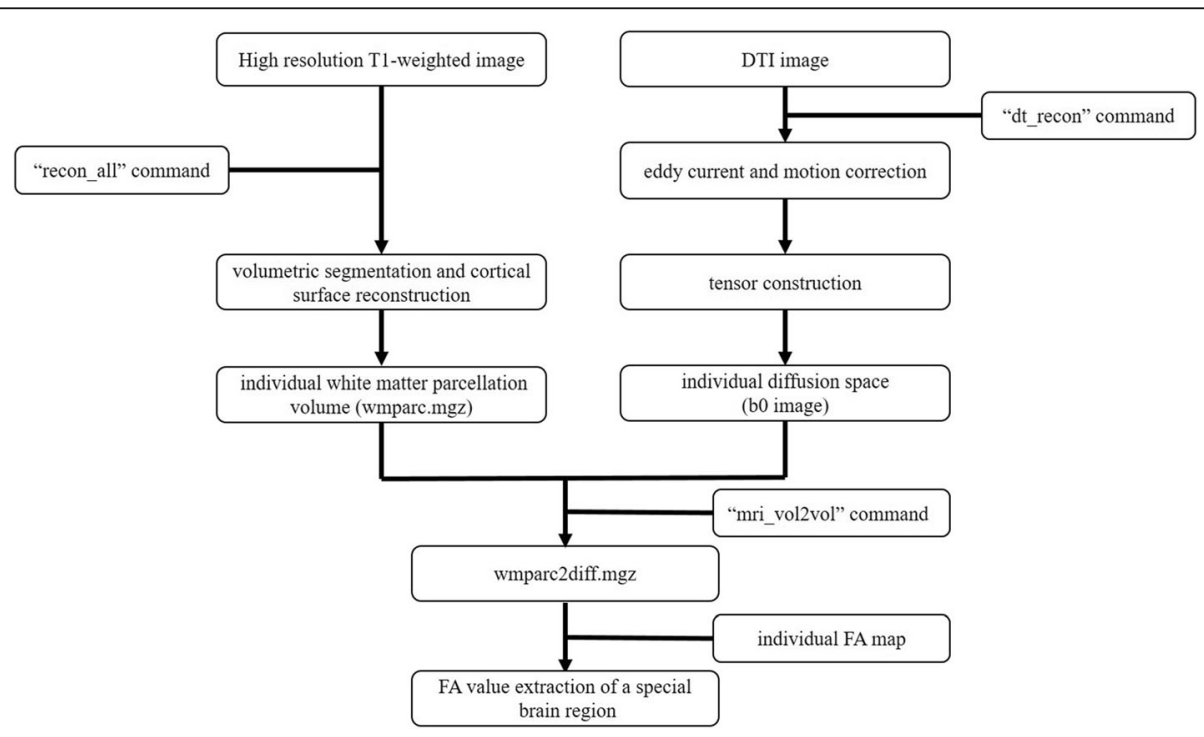

Fig. 1 The preprocessing pipeline of imaging data. Note: DTI, diffusion tensor imaging; FA, fractional anisotropy 


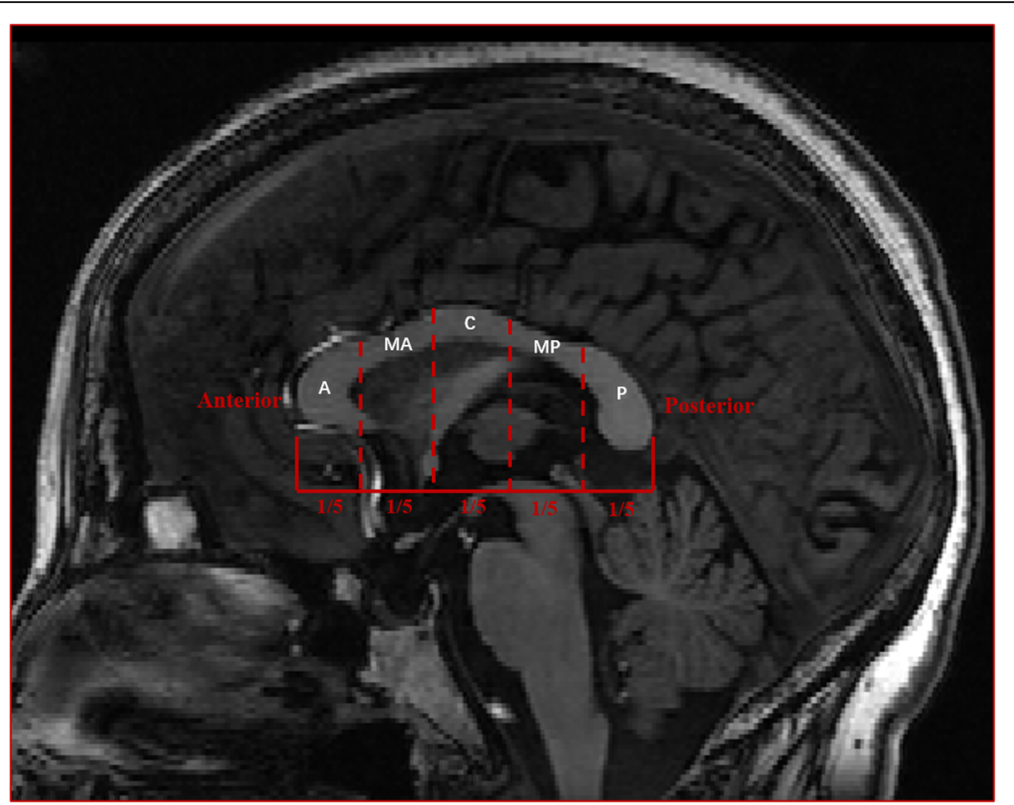

Fig. 2 Corpus callosum was divided into five components of equal length along its' primary eigendirection, corresponding to functional subdivisions, namely: anterior, mid-anterior, central, mid-posterior and posterior portions. Note: A, anterior (rostrum); MA, mid-anterior (genu); C, central (truncus/ body); MP, mid-posterior (anterior splenium); P, posterior (posterior splenium)

\section{Statistical analysis}

One-way analysis of variance (ANOVA), two sample ttests or chi-square tests were used to compare the demographic and clinical characteristics of the sample, including age, sex, education, illness duration, medications, TIV and PANSS scores.

Before analyzing anatomical characteristics of the CC, we firstly removed extreme outliers in the study (individual volume or FA values greater than/less than 3 standard deviations from group mean). Then, we test the interactions of diagnostic group with sex or age for callosal volumes and FA values using general linear model (GLM). Multivariate analysis of covariance (MANCOVA) was used to test for between-group differences in subregional volumes and FA values of the CC. Univariate analysis of covariance (ANCOVA) was used to test for group differences in $\mathrm{CC}$ total volume. In these statistical models, diagnostic group (CT-SCZ, RT-SCZ, NC-SCHZ, HCs) and sex (females vs. males) were considered as between-subject factors, and age, years of education and daily chlorpromazine equivalent dosage were regarded as covariates [17]. Two-sample $t$ tests with false discovery rate (FDR) correction were performed for post-hoc comparisons once significant main effects were observed. We also examined correlations of clinical symptoms with statistically significant group differences in callosal metrics using Pearson correlation analysis. All analyses were performed using SPSS (version 18.0) and statistical significance was set at two-tailed $P<0.05$.

\section{Results}

\section{Demographic data}

The clinical and demographic data are displayed in Table 1. Age, sex, and TIV were not significantly different among groups, though there was a significant difference in education $(P=0.001)$. PANSS total and subscale scores in NT-SCZ were significantly higher than treated patients $(P<0.001)$ and there was no significant difference in PANSS scores between RT-SCZ and CT-SCZ. In addition, mean daily chlorpromazine equivalent doses in RT-SCZ were significantly larger than that in CT-SCZ $(P=0.019)$.

\section{Groups differences in callosal volumes}

There were no any significant interactions between sex/age and diagnostic group for callosal volumes. Univariate ANCOVA showed a significant main effect of diagnostic group on total CC volume $(F=3.213, P=0.027)$. Pairwise comparison analyses revealed that NT-SCZ had significantly reduced $\mathrm{CC}$ volume compared to $\mathrm{HCs}(P=0.004, P<0.05$ corrected with FDR) (Table 2), while the other groups did not significantly differ from each other. MANCOVA of subregional volumes of the $C C$ showed a significant main effect of diagnostic group $(F=2.228, P=0.006)$, where significant differences in the volume of the mid-anterior $\mathrm{CC}$ region were shown among the four groups $(F=6.380, P=0.001)$ (Fig. 3). Specifically, post-hoc analyses showed significantly higher mid-anterior CC volume in HCs compared with both NTSCZ $(P<0.001, P<0.05$ corrected with FDR) and CT-SCZ $(P=0.012, P<0.05$ corrected with FDR). Moreover, RT- 
Table 1 Demographic and clinical characteristics of study participants

\begin{tabular}{|c|c|c|c|c|c|c|c|c|c|c|c|c|}
\hline & \multirow{2}{*}{$\begin{array}{l}\text { CT-SCZ, } \\
N=23 \\
\text { Mean } \pm \\
\text { SD }\end{array}$} & \multirow{2}{*}{$\begin{array}{l}\text { RT-SCZ, } \\
N=19 \\
\text { Mean } \pm \\
\text { SD }\end{array}$} & \multirow{2}{*}{$\begin{array}{l}\text { NT-SCZ, } \\
N=23 \\
\text { Mean } \pm \\
\text { SD }\end{array}$} & \multirow{2}{*}{$\begin{array}{l}\text { HCs, } N= \\
35 \\
\text { Mean } \pm \\
\text { SD }\end{array}$} & \multirow{2}{*}{$\begin{array}{l}\text { Statistics } \\
\text { (ANOVA, } \\
\text { t or } \mathrm{X}^{2} \text { ) }\end{array}$} & \multirow{2}{*}{$\begin{array}{l}p \\
\text { value }\end{array}$} & \multicolumn{6}{|c|}{ Post-hoc analyses } \\
\hline & & & & & & & $\begin{array}{l}\text { NT-SCZ } \\
\text { vs. HCs }\end{array}$ & $\begin{array}{l}\text { NT-SCZ } \\
\text { vs. RT- } \\
\text { SCZ }\end{array}$ & $\begin{array}{l}\text { NT-SCZ } \\
\text { vs. CT- } \\
\text { SCZ }\end{array}$ & $\begin{array}{l}\text { RT- } \\
\text { SCZ } \\
\text { vs. } \\
\text { CT- } \\
\text { SCZ }\end{array}$ & $\begin{array}{l}\text { RT-SCZ } \\
\text { vs. HCs }\end{array}$ & $\begin{array}{l}\text { CT-SCZ } \\
\text { vs. HCs }\end{array}$ \\
\hline Age (years) & $\begin{array}{l}48.96 \pm \\
6.76\end{array}$ & $\begin{array}{l}43.63 \pm \\
7.83\end{array}$ & $\begin{array}{l}44.26 \pm \\
13.619\end{array}$ & $\begin{array}{l}44.29 \pm \\
2.44\end{array}$ & 2.105 & 0.105 & NS & NS & NS & $0.038^{*}$ & NS & $0.036^{*}$ \\
\hline Gender (M/F) & $14 / 9$ & $11 / 8$ & $12 / 11$ & $13 / 22$ & 3.918 & 0.270 & NS & NS & NS & NS & NS & NS \\
\hline Education (years) & $\begin{array}{l}9.43 \pm \\
2.84\end{array}$ & $\begin{array}{l}10.58 \pm \\
3.37\end{array}$ & $\begin{array}{l}6.83 \pm \\
4.78\end{array}$ & $\begin{array}{l}8.01 \pm \\
1.77\end{array}$ & 5.634 & 0.001 & NS & $<.001 * * *$ & $0.001^{* *}$ & NS & $0.006^{* *}$ & NS \\
\hline Illness duration (years) & $\begin{array}{l}18.34 \pm \\
7.67\end{array}$ & $\begin{array}{l}14.11 \pm \\
8.43\end{array}$ & $\begin{array}{l}16.44 \pm \\
10.88\end{array}$ & - & 1.114 & 0.345 & - & NS & NS & NS & - & - \\
\hline \multicolumn{13}{|l|}{ PANSS score } \\
\hline Total & $\begin{array}{l}57.21 \pm \\
11.42\end{array}$ & $\begin{array}{l}49.44 \pm \\
12.99\end{array}$ & $\begin{array}{l}92.26 \pm \\
19.53\end{array}$ & - & 42.681 & $\begin{array}{l}< \\
0.001\end{array}$ & - & $\begin{array}{l}<.001 * * * \\
0.001\end{array}$ & $\begin{array}{l}< \\
0.001 * * *\end{array}$ & NS & - & - \\
\hline Positive symptoms & $\begin{array}{l}10.79 \pm \\
3.09\end{array}$ & $\begin{array}{l}9.61 \pm \\
2.91\end{array}$ & $\begin{array}{l}23.09 \pm \\
6.61\end{array}$ & - & 47.737 & $\begin{array}{l}< \\
0.001\end{array}$ & - & $\begin{array}{l}< \\
0.001 * * *\end{array}$ & $\begin{array}{l}< \\
0.001 * * *\end{array}$ & NS & - & - \\
\hline Negative symptoms & $\begin{array}{l}18.79 \pm \\
5.59\end{array}$ & $\begin{array}{l}14.83 \pm \\
5.92\end{array}$ & $\begin{array}{l}25.57 \pm \\
9.59\end{array}$ & - & 10.374 & $\begin{array}{l}< \\
0.001\end{array}$ & - & $\begin{array}{l}< \\
0.001^{* * *}\end{array}$ & $\begin{array}{l}<.001 * * * \\
0.01\end{array}$ & NS & - & - \\
\hline $\begin{array}{l}\text { General } \\
\text { psychopathological } \\
\text { symptoms }\end{array}$ & $\begin{array}{l}27.64 \pm \\
5.32\end{array}$ & $\begin{array}{l}24.83 \pm \\
5.59\end{array}$ & $\begin{array}{l}43.61 \pm \\
8.47\end{array}$ & - & 43.858 & $\begin{array}{l}< \\
0.001\end{array}$ & - & $\begin{array}{l}<.001 * * * \\
0.001\end{array}$ & $\begin{array}{l}< \\
0.001 * * *\end{array}$ & NS & - & - \\
\hline $\begin{array}{l}\text { Chlorpromazine } \\
\text { equivalents (mg/ } \\
\text { day) }\end{array}$ & $\begin{array}{l}233.99 \pm \\
101.62\end{array}$ & $\begin{array}{l}316.25 \pm \\
115.46\end{array}$ & - & - & 2.455 & 0.019 & - & - & - & - & - & - \\
\hline $\begin{array}{l}\text { Total Intracranial } \\
\text { Volume (TIV) }\left(\mathrm{cm}^{3}\right)\end{array}$ & $\begin{array}{l}1431.73 \pm \\
159.18\end{array}$ & $\begin{array}{l}1442.26 \pm \\
175.39\end{array}$ & $\begin{array}{l}1401.05 \pm \\
132.88\end{array}$ & $\begin{array}{l}1394.01 \pm \\
224.44\end{array}$ & 0.401 & 0.753 & NS & NS & NS & NS & NS & NS \\
\hline
\end{tabular}

Note: ANOVA analysis of variance, CT-SCZ clozapine-treated schizophrenia patients, RT-SCZ risperidone-treated schizophrenia patients, NT-SCZ never-treated schizophrenia patients, HCs healthy controls, PANSS Positive and Negative Syndrome Scale, NS not significant, ${ }^{*}$, Significant group difference at $P<0.05 ;{ }^{* *}, P<$ $0.01 ; * * *, P<0.001$

SCZ had significantly increased volume compared to NTSCZ $(P=0.024, P<0.05$ corrected with FDR). MANCOVA test also showed a significant difference in the volume of the central $\mathrm{CC}$ region among the four participant groups $(F=$ $3.318, P=0.023)$. Post-hoc analyses revealed that such difference was between HCs and NT-SCZ $(P=0.006, P<0.05$ corrected with FDR). There were no significant group differences in the volumes of other three CC subregions.

\section{Groups differences in callosal FA values}

FA values in the five CC subregions are listed in Table 3. No interactions of diagnostic group with sex or age for

Table 2 Corpus callosum volumes $\left(\mathrm{mm}^{3}\right)$ in CT-SCZ, RT-SCZ, NT-SCZ and HCS

\begin{tabular}{|c|c|c|c|c|c|c|c|c|c|c|c|c|}
\hline \multirow{2}{*}{$\begin{array}{l}\text { Corpus } \\
\text { callosum }\end{array}$} & \multirow{2}{*}{$\begin{array}{l}\text { CT-SCZ, } N=23 \\
\text { Mean } \pm S D\end{array}$} & \multirow{2}{*}{$\begin{array}{l}\text { RT-SCZ, } N=19 \\
\text { Mean } \pm \text { SD }\end{array}$} & \multirow{2}{*}{$\begin{array}{l}\text { NT-SCZ, } N=23 \\
\text { Mean } \pm \text { SD }\end{array}$} & \multirow{2}{*}{$\begin{array}{l}H C s, N=35 \\
\text { Mean } \pm S D\end{array}$} & \multirow{2}{*}{$\begin{array}{l}\text { F } \\
\text { value }\end{array}$} & \multirow{2}{*}{$\begin{array}{l}p \\
\text { value }\end{array}$} & \multicolumn{6}{|c|}{ Post-hoc analyses } \\
\hline & & & & & & & $\begin{array}{l}\text { NT-SCZ } \\
\text { vs. HCs }\end{array}$ & $\begin{array}{l}\text { NT- } \\
\text { SCZ } \\
\text { vS. RT- } \\
\text { SCZ }\end{array}$ & $\begin{array}{l}\text { NT- } \\
\text { SCZ } \\
\text { vs. } \\
\text { CT- } \\
\text { SCZ }\end{array}$ & $\begin{array}{l}\text { RT- } \\
\text { SCZ } \\
\text { vs. } \\
\text { CT- } \\
\text { SCZ }\end{array}$ & $\begin{array}{l}\text { RT- } \\
\text { SCZ } \\
\text { vs. } \\
\text { HCs }\end{array}$ & $\begin{array}{l}\text { CT- } \\
\text { SCZ } \\
\text { vs. } \\
\text { HCs }\end{array}$ \\
\hline Anterior & $916.73 \pm 145.59$ & $866.72 \pm 155.71$ & $831.76 \pm 110.77$ & $845.43 \pm 124.69$ & 0.601 & 0.616 & NS & NS & NS & NS & NS & NS \\
\hline $\begin{array}{l}\text { Mid- } \\
\text { anterior }\end{array}$ & $530.28 \pm 135.11$ & $590.23 \pm 126.91$ & $460.38 \pm 76.92$ & $611.49 \pm 150.69$ & 6.380 & 0.001 & $\begin{array}{l}< \\
0.001^{* * *}\end{array}$ & $0.024^{*}$ & NS & NS & NS & $0.012^{*}$ \\
\hline Central & $546.32 \pm 152.74$ & $538.48 \pm 123.73$ & $490.27 \pm 114.93$ & $600.16 \pm 139.44$ & 3.318 & 0.023 & $0.006^{* *}$ & NS & NS & NS & NS & NS \\
\hline $\begin{array}{l}\text { Mid- } \\
\text { posterior }\end{array}$ & $479.59 \pm 96.39$ & $500.46 \pm 107.27$ & $454.47 \pm 87.86$ & $503.92 \pm 78.22$ & 1.287 & 0.284 & NS & NS & NS & NS & NS & NS \\
\hline Posterior & $942.36 \pm 157.09$ & $949.00 \pm 172.78$ & $835.62 \pm 128.31$ & $900.63 \pm 148.86$ & 1.995 & 0.120 & NS & NS & NS & NS & NS & NS \\
\hline Total & $3415.29 \pm 524.04$ & $3444.89 \pm 553.07$ & $3072.52 \pm 363.73$ & $3450.67 \pm 414.81$ & 3.213 & 0.027 & $0.004^{* *}$ & NS & NS & NS & NS & NS \\
\hline
\end{tabular}

Note: $C T$-SCZ clozapine-treated schizophrenia patients, $R T$-SCZ risperidone-treated schizophrenia patients, NT-SCZ never-treated schizophrenia patients, $H C S$ healthy controls, NS not significant, ${ }^{*}$, Significant group difference at $P<0.05 ;{ }^{* *}, P<0.01 ;{ }^{* * *}, P<0.001$ 


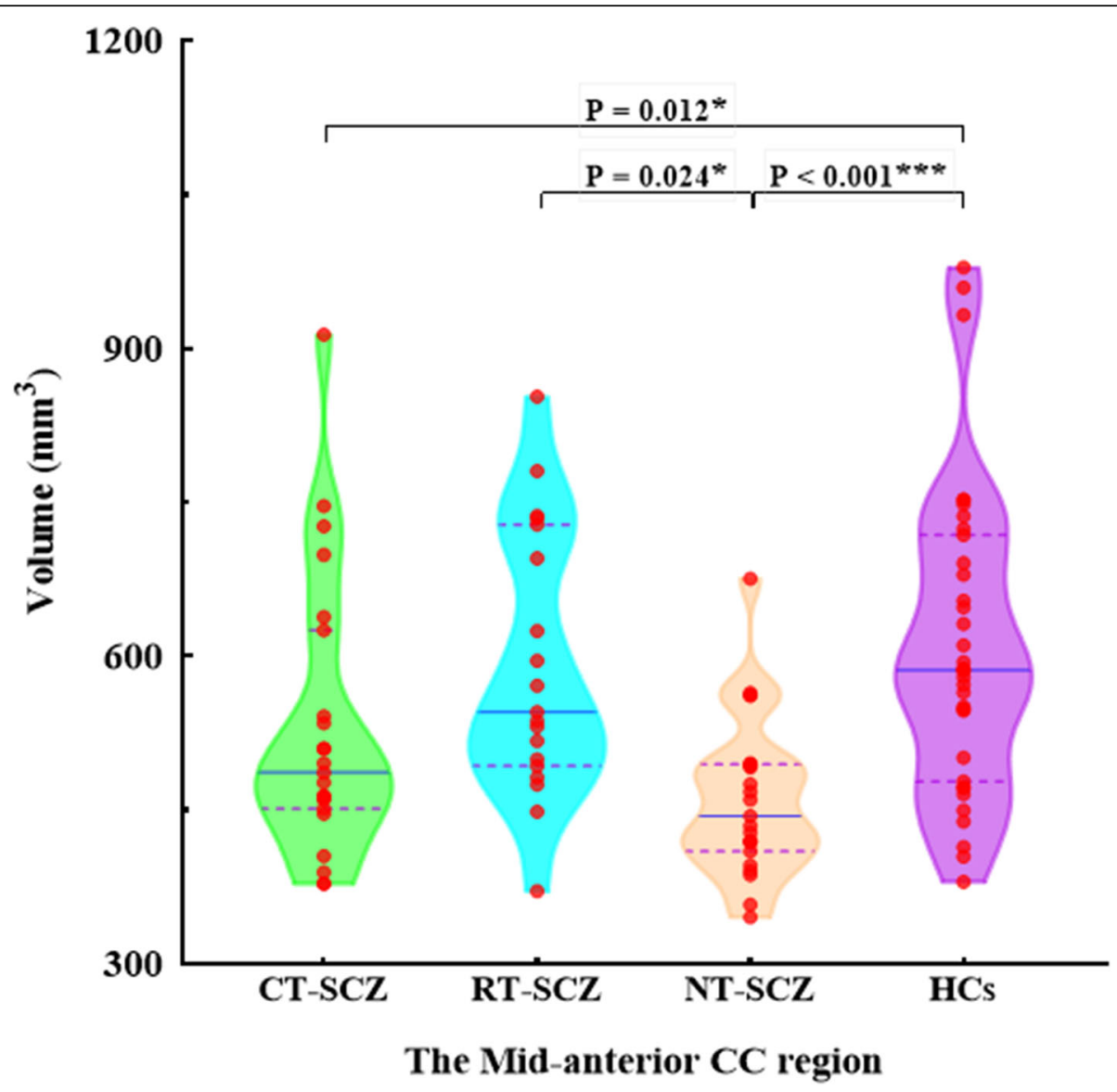

Fig. 3 Volume $\left(\mathrm{mm}^{3}\right)$ of the mid-anterior CC region in CT-SCZ, RT-SCZ, NT-SCZ and HCs. Note: CT-SCZ, clozapine-treated schizophrenia patients; RT-SCZ, risperidone-treated schizophrenia patients; NT-SCZ, never-treated schizophrenia patients; HCs, healthy controls; CC, corpus callosum; *, Significant group difference at $P<0.05 ;{ }^{* *}, P<0.01 ;{ }^{* *}, P<0.001$

callosal FA values were statistically different. MANCOVA test showed a significant main effect of diagnostic group $(F=1.723, \quad P=0.047)$, and there were significant differences in $\mathrm{FA}$ values of the anterior $\mathrm{CC}$ region among the four groups $(F=4.761, P=0.004)$ (Fig. 4). Post-hoc analyses showed that the FA values of the anterior $\mathrm{CC}$ region in $\mathrm{HCs}$ were significantly greater than that in NT-SCZ $(P=0.001, P<0.05$ corrected with
FDR), while there were no significant differences in FA values of this $C C$ region between treated patients and HCs. In addition, both RT-SCZ and CT-SCZ had significantly increased FA values in the anterior region of the CC in contrast with NT-SCZ $(P=0.008 \& P=0.023$, $P<0.05$ corrected with FDR). There were no significant group differences in FA values of other four CC subregions.

Table 3 Corpus callosum fractional anisotropy (FA) values in CT-SCZ, RT-SCZ, NT-SCZ and HCs

\begin{tabular}{|c|c|c|c|c|c|c|c|c|c|c|c|c|}
\hline \multirow{2}{*}{$\begin{array}{l}\text { Corpus } \\
\text { callosum }\end{array}$} & \multirow{2}{*}{$\begin{array}{l}\text { CT-SCZ, } \\
N=23 \\
\text { Mean } \pm \\
\text { SD }\end{array}$} & \multirow{2}{*}{$\begin{array}{l}\text { RT-SCZ, } \\
N=19 \\
\text { Mean } \pm \\
\text { SD }\end{array}$} & \multirow{2}{*}{$\begin{array}{l}\text { NT-SCZ, } \\
N=23 \\
\text { Mean } \pm \\
\text { SD }\end{array}$} & \multirow{2}{*}{$\begin{array}{l}\text { HCs, } N= \\
35 \\
\text { Mean } \pm \\
\text { SD }\end{array}$} & \multirow{2}{*}{$\begin{array}{l}F \\
\text { value }\end{array}$} & \multirow{2}{*}{$\begin{array}{l}p \\
\text { value }\end{array}$} & \multicolumn{6}{|c|}{ Post-hoc analyses } \\
\hline & & & & & & & $\begin{array}{l}\text { NT-SCZ } \\
\text { vs. HCs }\end{array}$ & $\begin{array}{l}\text { NT-SCZ } \\
\text { vs. RT-SCZ }\end{array}$ & $\begin{array}{l}\text { NT-SCZ } \\
\text { vs. CT- } \\
\text { SCZ }\end{array}$ & $\begin{array}{l}\text { RT-SCZ } \\
\text { vs. CT- } \\
\text { SCZ }\end{array}$ & $\begin{array}{l}\text { RT-SCZ } \\
\text { vs. HCs }\end{array}$ & $\begin{array}{l}\text { CT-SCZ } \\
\text { vs. HCs }\end{array}$ \\
\hline Anterior & $0.54 \pm 0.04$ & $0.57 \pm 0.05$ & $0.50 \pm 0.06$ & $0.55 \pm 0.04$ & 4.761 & 0.004 & $0.001^{* *}$ & $0.008^{* *}$ & $0.023^{*}$ & NS & NS & NS \\
\hline Mid-anterior & $0.43 \pm 0.06$ & $0.42 \pm 0.04$ & $0.43 \pm 0.05$ & $0.42 \pm 0.04$ & 0.530 & 0.663 & NS & NS & NS & NS & NS & NS \\
\hline Central & $0.45 \pm 0.08$ & $0.45 \pm 0.06$ & $0.47 \pm 0.05$ & $0.47 \pm 0.06$ & 0.342 & 0.759 & NS & NS & NS & NS & NS & NS \\
\hline Mid-posterior & $0.41 \pm 0.07$ & $0.42 \pm 0.07$ & $0.42 \pm 0.06$ & $0.41 \pm 0.04$ & 1.016 & 0.389 & NS & NS & NS & NS & NS & NS \\
\hline Posterior & $0.60 \pm 0.05$ & $0.64 \pm 0.06$ & $0.63 \pm 0.06$ & $0.63 \pm 0.04$ & 0.972 & 0.409 & NS & NS & NS & NS & NS & NS \\
\hline
\end{tabular}

Note: $C T$-SCZ clozapine-treated schizophrenia patients, $R T$-SCZ risperidone-treated schizophrenia patients, $N T$-SCZ never-treated schizophrenia patients, $H C S$ healthy controls, NS not significant, ${ }^{*}$, Significant group difference at $P<0.05 ;{ }^{* *}, P<0.01 ; * * *, P<0.001$ 


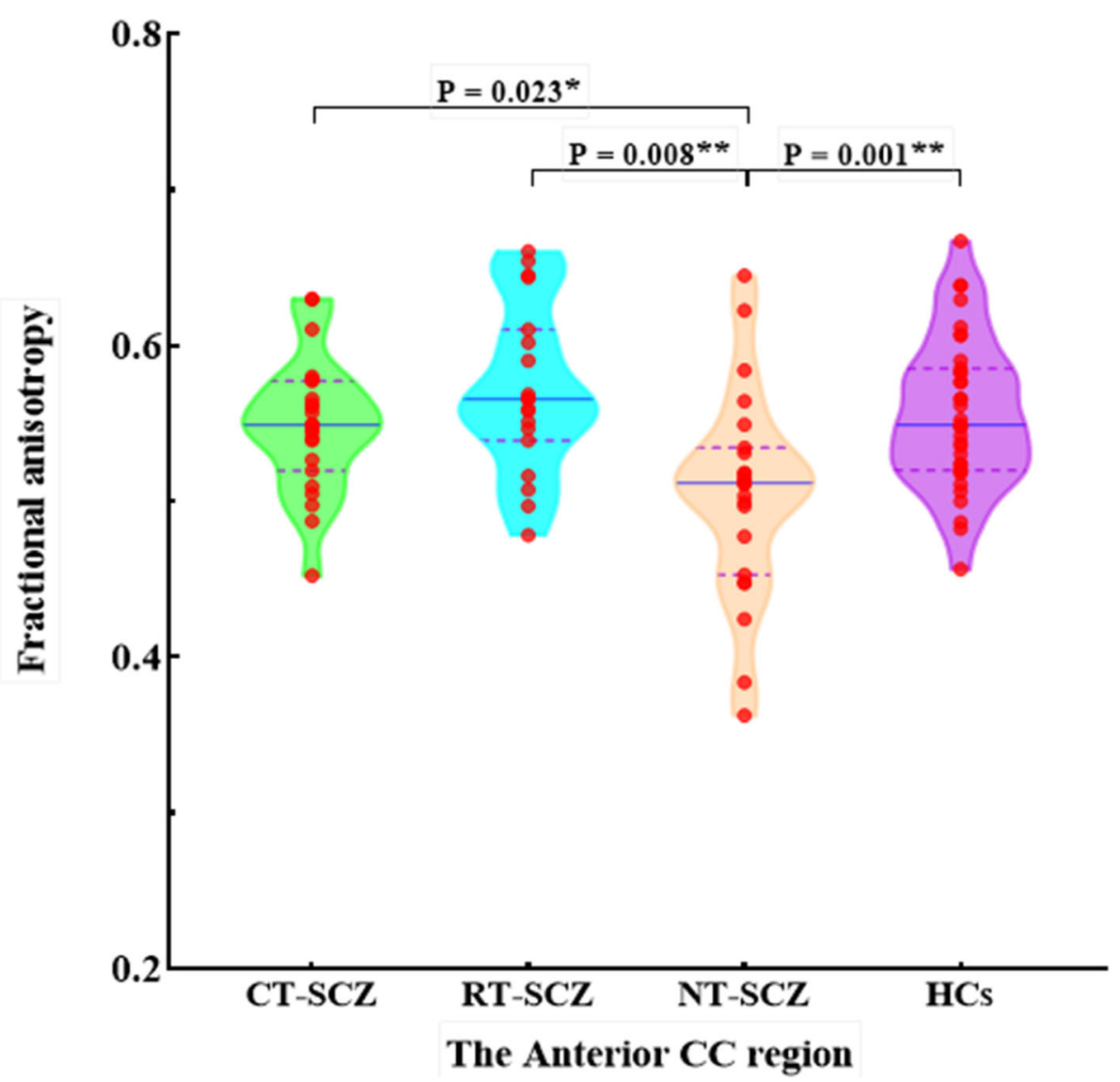

Fig. 4 Fractional anisotropy (FA) of the anterior CC region in CT-SCZ, RT-SCZ, NT-SCZ and HCs. Note: CT-SCZ, clozapine-treated schizophrenia patients; RT-SCZ, risperidone-treated schizophrenia patients; NT-SCZ, never-treated schizophrenia patients; HCs, healthy controls; CC, corpus callosum; *, Significant group difference at $P<0.05 ;{ }^{*}, P<0.01 ;{ }^{* *}, P<0.001$

\section{Relationships with clinical symptoms}

The volumes of the mid-anterior $\mathrm{CC}$ region and the FA values of the anterior CC region in patients were not significantly associated with PANSS total or subscale scores.

\section{Discussion}

To the best of our knowledge, this is the first study to date investigating the impact of long-term monotherapy of clozapine and risperidone on callosal structure in chronic schizophrenia. Our analyses demonstrated significant reductions of callosal volumes in NT-SCZ in comparison with $\mathrm{HCs}$, which were located in the central and mid-anterior region of the $\mathrm{CC}$. We also found that FA values of the anterior CC region in NT-SCZ significantly reduced compared to HCs. Moreover, both RTSCZ and CT-SCZ showed significantly increased FA values in the anterior CC region compared to NT-SCZ, and only RT-SCZ had larger volume in the mid-anterior $\mathrm{CC}$ region compared with NT-SCZ. Together, these findings suggest that chronic exposure to clozapine and risperidone may have different effects on callosal structure in schizophrenia.

The findings of our present study agree well with other studies in the literature demonstrating that chronic schizophrenia patients without any antipsychotic medications were associated with smaller volumes and FA values of the $\mathrm{CC}$ in comparison with $\mathrm{HCs}[3,17,19-$ 21]. As an extension of prior findings, one important observation here is that callosal deficits were mainly located in the anterior and mid-anterior CC region. White matter fibers passing through these subregions are responsible for connecting the frontal lobes [22, 23]. Therefore, anatomical alterations in the anterior and mid-anterior region of the CC may be related to structural and functional abnormalities of the frontal lobe in schizophrenia, which generate delusions and hallucinations [24, 25]. However, other studies showed that chronic schizophrenia patients had more widespread deficits that were located in both anterior and posterior region of the $\mathrm{CC}[3,19,20]$. This discrepancy may be due to sample heterogeneities related to race, handedness, sex, and age, and to methodological differences [3]. 
Apart from anterior and mid-anterior CC, we also observed significant volume reduction in central $\mathrm{CC}$ in never-treated patients compared with $\mathrm{HCs}$, which is in line with findings from Collinson et al. [17]. Furthermore, it is suggested that alterations of this subregion with time in schizophrenia may be associated with stage of illness [17]. Thus, it is interesting to explore whether structural alterations in central $\mathrm{CC}$ are a stable biomarker to predict the developmental trajectory of schizophrenia in future studies.

The observation that micro- and macrostructural abnormalities of the CC in schizophrenia were located in different subregions is in line with other two studies [19, 24]. Here, we found that alterations of callosal volume were in the mid-anterior and central region, and abnormalities of white matter integrity were only in the anterior region of the CC. It has been proposed that changes in the number of axons and the degree of myelination may lead to the changes in white matter volume but not anisotropy [17, 26, 27]. Since the index of anisotropy is related with fiber integrity $[28,29]$, its change in schizophrenia patients may relate to disruptions of oligodendrocytes and/or myelin surrounding axons because of inflammation or dysregulations of neuroinflammatory responses [30-33]. Our findings suggest different pathophysiological processes in these subregions of the CC.

The current findings, together with findings from previous studies, suggest that chronic exposure to antipsychotics may have an impact on anatomical organization of the CC in schizophrenia $[11,12]$. In this study, both CT-SCZ and RT-SCZ showed significantly increased FA values in the anterior $C C$ region in comparison with NT-SCZ. Prior studies have demonstrated that antipsychotic medications may modulate inflammations and immune responses through reduced activation of microglia and macrophages, increased level of antiinflammatory cytokines, and inhibition of the release of proinflammatory cytokines [34, 35]. And animal studies in the past decade showed that chronic exposure to antipsychotic medications attenuated white matter lesions [36-39]. Therefore, clozapine and risperidone may repair microstructural deficits of the $\mathrm{CC}$ by reducing inflammation or immune responses. Interestingly, only schizophrenia patients receiving long-term risperidone, not clozapine, showed significantly increased volumes of mid-anterior CC. Evidences from gene expression profiling and neuroimaging studies support the hypothesis that dysregulation of the dopaminergic system is associated with myelination impairment in psychiatric disorders $[40,41]$. It has been suggested that risperidone and clozapine have different affinity for dopamine receptors [10]. Bartzokis et al. also found that antipsychotic medications differently mitigated myelination deficits in schizophrenia depending on their affinities to dopamine receptors $[8,42,43]$. Therefore, our findings may suggest that different impacts of two drugs on callosal volumes are related to their different abilities in modulating the dopaminergic system.

There are several limitations in the present study. First, because that this study is a cross-sectional design and it lack of random assignments to different antipsychotic medications for schizophrenia patients, it should be careful to interpret our current findings. However, it is unethical and challenging to request the patients to receive a single antipsychotic treatment for over five years in a longitudinal study with a randomize design. Therefore, our cross-sectional design may be a feasible method to explore the effects of long-term usage of antipsychotics on human brain. Second, the sample size in this study is relatively small, and may be not completely representative. Third, the usage of nonantipsychotic medications was not controlled according to individual clinical condition. Four, as the most widely used index of DTI, FA essentially combines information about diffusion direction and diffusion speed thus provides an overall summary of fiber integrity [44]. Therefore, FA is our primary parameter of interest. In addition, more diffusion parameters will be explored in the future studies.

\section{Conclusions}

Using comparing schizophrenia patients with long-term mono-antipsychotic medications with un-medicated chronic patients and HCs, the present study displays a more severe change of callosal anatomy in never-treated patients and demonstrates differential alterations of callosal structure in patients with different antipsychotic treatments. These findings suggest that the pathology itself is responsible for cerebral abnormalities in schizophrenia and that chronic exposure to antipsychotic medications may have an impact on white matter structure of schizophrenia patients, especially in those with risperidone treatment.

\section{Abbreviations \\ ANOVA: analysis of variance; ANCOVA: analysis of covariance; CC: corpus callosum; CT-SCZ: clozapine-treated schizophrenia patients; DTI: diffusion tensor imaging; FA: fractional anisotropy; FDR: false discovery rate; HCs: healthy controls; MANCOVA: multivariate analysis of covariance; MRI: magnetic resonance imaging; NT-SCZ: never-treated schizophrenia patients; PANSS: Positive and Negative Symptom Scale; RT-SCZ: risperidone- treated schizophrenia patients; TIV: total intracranial volume.}

\section{Acknowledgements}

The authors want to express their sincere gratitude to all the teachers and students who participated in this survey.

\section{Authors' contributions}

Su Lui contributed to the conception and design of the study. Bo Tao, Yuan Xiao, Wenjing Zhang and Chengmin Yang contributed to the acquisition, or analysis and interpretation of data. Bo Tao, Yuan Xiao, Hengyi Cao, Rebekka Lencer, Qiyong Gong and Su Lui contributed to the drafting of the manuscript, while all authors made critical revision of the manuscript for 
important intellectual content and gave final approval of the version to be published. The authors read and approved the final manuscript.

\section{Funding}

This work was supported by National Natural Science Foundation of China (Grant Nos. 81671664 to S. L, 81901705 to Y.X.), grants from the Humboldt Foundation (Lui, Xiao), China Postdoctoral Science Foundation (2019 M663513), Post-Doctor Research Project of West China Hospital of Sichuan University (2020HXBH005), the Postdoctoral Interdisciplinary Research Project of Sichuan University, Sichuan Science and Technology Program (2020YFS0116), and 1.3.5 Project for Disciplines of Excellence, West China Hospital, Sichuan University (Project No. ZYYC08001, ZYJC18020 to S.L.).

\section{Availability of data and materials}

The datasets generated and analysed during the current study are not publicly available due to their containing information that could compromise patients' privacy, but are available from the corresponding author on reasonable request.

\section{Declarations}

\section{Ethics approval and consent to participate}

The study methods were performed in accordance with the relevant guidelines and regulations. Ethical approval for this study was approved by the research ethics committee of West China Hospital of Sichuan University. All participants provided written informed consent for study procedures, and informed consent for schizophrenia patients was obtained from their parents or legal guardians.

\section{Consent for publication}

Not applicable.

\section{Competing interests}

Dr. Zhang consults to VeraSci. Other authors declare no conflicts of interest in relation to the subject of this study.

\section{Author details}

${ }^{1}$ Huaxi MR Research Center (HMRRC), Functional and Molecular Imaging Key Laboratory of Sichuan Province, Department of Radiology, West China Hospital, Sichuan University, 37 Guo Xuexiang, Chengdu 610041, China. ${ }^{2}$ Psychoradiology Research Unit of the Chinese Academy of Medical Sciences, West China Hospital of Sichuan University, Chengdu, China. ${ }^{3}$ Center for Psychiatric Neuroscience, Feinstein Institute for Medical Research, Manhasset, NY, USA. ${ }^{4}$ Division of Psychiatry Research, Zucker Hillside Hospital, Glen Oaks, NY, USA. ${ }^{5}$ Department of Psychiatry and Psychotherapy, University of Lübeck, Lübeck, Germany.

\section{Received: 11 March 2021 Accepted: 13 October 2021}

\section{Published online: 30 October 2021}

\section{References}

1. Walterfang M, Velakoulis D. Callosal morphology in schizophrenia: what can shape tell us about function and illness? Br J Psychiatry. 2014;204(1):9-11. https://doi.org/10.1192/bjp.bp.113.132357.

2. Shahab S, Stefanik L, Foussias G, Lai MC, Anderson KK, Voineskos AN. Sex and diffusion tensor imaging of white matter in schizophrenia: a systematic review plus Meta-analysis of the Corpus callosum. Schizophr Bull. 2018;44(1): 203-21. https://doi.org/10.1093/schbul/sbx049.

3. Zhuo C, Liu M, Wang L, Tian H, Tang J. Diffusion tensor MR imaging evaluation of Callosal abnormalities in schizophrenia: a Meta-analysis. PLoS One. 2016;11(8):e0161406. https://doi.org/10.1371/journal.pone.0161406.

4. Arnone D, Mclntosh AM, Tan GM, Ebmeier KP. Meta-analysis of magnetic resonance imaging studies of the corpus callosum in schizophrenia. Schizophr Res. 2008;101(1-3):124-32. https://doi.org/10.1016/j.schres.2008.01.005.

5. de Moura MTM, Zanetti MV, Duran FLS, Schaufelberger MS, Menezes PR, Scazufca M, et al. Corpus callosum volumes in the 5years following the firstepisode of schizophrenia: effects of antipsychotics, chronicity and maturation. Neuroimage Clin. 2018;18:932-42. https://doi.org/10.1016/j.nicl.2 018.03.015.

6. Mitelman SA, Nikiforova YK, Canfield EL, Hazlett EA, Brickman AM, Shihabuddin L, et al. A longitudinal study of the corpus callosum in chronic schizophrenia. Schizophr Res. 2009;114(1-3):144-53. https://doi.org/10.1016/ j.schres.2009.07.021.

7. Leroux E, Vandevelde A, Trehout M, Dollfus S. Abnormalities of fronto-subcortical pathways in schizophrenia and the differential impacts of antipsychotic treatment: a DT-based tractography study. Psychiatry Res Neuroimaging. 2018;280:22-9. https:// doi.org/10.1016/.jpscychresns.2018.08.008.

8. Bartzokis G, Lu PH, Stewart SB, Oluwadara B, Lucas AJ, Pantages J, et al. In vivo evidence of differential impact of typical and atypical antipsychotics on intracortical myelin in adults with schizophrenia. Schizophr Res. 2009;113(23):322-31. https://doi.org/10.1016/j.schres.2009.06.014.

9. Howes OD, McCutcheon R, Agid O, de Bartolomeis A, van Beveren NJ, Birnbaum ML, et al. Treatment-resistant schizophrenia: treatment response and resistance in psychosis (TRRIP) working group consensus guidelines on diagnosis and terminology. Am J Psychiatry. 2017;174(3):216-29. https://doi. org/10.1176/appi.ajp.2016.16050503.

10. Tsermpini EE, Assimakopoulos K, Bartsakoulia M, Iconomou G, Papadima EM Mitropoulos K, et al. Individualizing clozapine and risperidone treatment for schizophrenia patients. Pharmacogenomics. 2014;15(1):95-110. https://doi. org/10.2217/pgs.13.219.

11. Luo C, Lencer R, Hu N, Xiao Y, Zhang W, Li S, et al. Characteristics of white matter structural networks in chronic schizophrenia treated with clozapine or risperidone and those never-treated. Int J Neuropsychopharmacol. 2020; 23(12):799-810. https://doi.org/10.1093/ijnp/pyaa061.

12. Xiao $Y$, Sun $H$, Shi S, Jiang $D$, Tao B, Zhao $Y$, et al. White matter abnormalities in never-treated patients with long-term schizophrenia. Am J Psychiatry. 2018;175(11):1129-36. https://doi.org/10.1176/appi.ajp.2018.1 7121402.

13. Singh SP, Cooper JE, Fisher HL, Tarrant CJ, Lloyd T, Banjo J, et al. Determining the chronology and components of psychosis onset: the Nottingham onset schedule (NOS). Schizophr Res. 2005;80(1):117-30. https://doi.org/10.1016/j.schres.2005.04.018.

14. Kay SR, Opler LA, Lindenmayer JP. Reliability and validity of the positive and negative syndrome scale for schizophrenics. Psychiatry Res. 1988;23(1):99110. https://doi.org/10.1016/0165-1781(88)90038-8.

15. Zhang W, Deng W, Yao L, Xiao Y, Li F, Liu J, et al. Brain structural abnormalities in a Group of Never-Medicated Patients with Long-Term Schizophrenia. Am J Psychiatry. 2015;172(10):995-1003. https://doi.org/10.11 76/appi.ajp.2015.14091108.

16. Segonne F, Dale AM, Busa E, Glessner M, Salat D, Hahn HK, et al. A hybrid approach to the skull stripping problem in MRI. Neuroimage. 2004;22(3): 1060-75. https://doi.org/10.1016/j.neuroimage.2004.03.032.

17. Collinson SL, Gan SC, Woon PS, Kuswanto C, Sum MY, Yang GL, et al. Corpus callosum morphology in first-episode and chronic schizophrenia: combined magnetic resonance and diffusion tensor imaging study of Chinese Singaporean patients. Br J Psychiatry. 2014;204(1):55-60. https://doi. org/10.1192/bjp.bp.113.127886

18. Buckner RL, Head D, Parker J, Fotenos AF, Marcus D, Morris JC, et al. A unified approach for morphometric and functional data analysis in young, old, and demented adults using automated atlas-based head size normalization: reliability and validation against manual measurement of total intracranial volume. Neuroimage. 2004;23(2):724-38. https://doi.org/1 0.1016/j.neuroimage.2004.06.018.

19. Madigand J, Trehout M, Delcroix N, Dollfus S, Leroux E. Corpus callosum microstructural and macrostructural abnormalities in schizophrenia according to the stage of disease. Psychiatry Res Neuroimaging. 2019;291: 63-70. https://doi.org/10.1016/j.pscychresns.2019.08.002.

20. Friedman Jl, Tang C, Carpenter D, Buchsbaum M, Schmeidler J, Flanagan L, et al. Diffusion tensor imaging findings in first-episode and chronic schizophrenia patients. Am J Psychiatry. 2008;165(8):1024-32. https://doi. org/10.1176/appi.ajp.2008.07101640.

21. Kubicki M, Park H, Westin CF, Nestor PG, Mulkern RV, Maier SE, et al. DTI and MTR abnormalities in schizophrenia: analysis of white matter integrity. Neurolmage. 2005;26(4):1109-18. https://doi.org/10.1016/j.neuroimage.2005. 03.026 .

22. Lee BY, Zhu XH, Li X, Chen W. High-resolution imaging of distinct human corpus callosum microstructure and topography of structural connectivity to cortices at high field. Brain Struct Funct. 2019;224(2):949-60. https://doi. org/10.1007/s00429-018-1804-0.

23. Hofer S, Frahm J. Topography of the human corpus callosum revisited-comprehensive fiber tractography using diffusion tensor magnetic 
resonance imaging. Neuroimage. 2006;32(3):989-94. https://doi.org/10.1016/ j.neuroimage.2006.05.044.

24. Knöchel C, Oertel-Knöchel V, Schönmeyer R, Rotarska-Jagiela A, van de Ven $V$, Prvulovic D, et al. Interhemispheric hypoconnectivity in schizophrenia: Fiber integrity and volume differences of the corpus callosum in patients and unaffected relatives. Neurolmage. 2012;59(2):926-34. https://doi.org/10.1 016/j.neuroimage.2011.07.088

25. Jardri R, Pouchet A, Pins D, Thomas P. Cortical activations during auditory verbal hallucinations in schizophrenia: a coordinate-based meta-analysis. Am J Psychiatry. 2011:168(1):73-81. https://doi.org/10.1176/appi.ajp.2010.09101522.

26. Hugenschmidt CE, Peiffer AM, Kraft RA, Casanova R, Deibler AR, Burdette JH, et al. Relating imaging indices of white matter integrity and volume in healthy older adults. Cereb Cortex. 2008;18(2):433-42. https://doi.org/10.1 093/cercor/bhm080

27. Cercignani M, Horsfield MA. The physical basis of diffusion-weighted MRI. J Neurol Sci. 2001;186(Suppl 1):S11-4. https://doi.org/10.1016/S0022-510X(01 )00486-5.

28. Alexander AL, Lee JE, Lazar M, Field AS. Diffusion tensor imaging of the brain. Neurotherapeutics J Am Soc Exp Neurother. 2007:4(3):316-29. https:// doi.org/10.1016/j.nurt.2007.05.011.

29. Le Bihan D, Mangin JF, Poupon C, Clark CA, Pappata S, Molko N, et al. Diffusion tensor imaging: concepts and applications. J Magn Reson Imaging. 2001;13(4):534-46. https://doi.org/10.1002/jmri.1076.

30. Fu G, Zhang W, Dai J, Liu J, Li F, Wu D, et al. Increased peripheral interleukin 10 relate to white matter integrity in schizophrenia. Front Neurosci. 2019;13. https://doi.org/10.3389/fnins.2019.00052.

31. Najjar S, Pearlman DM. Neuroinflammation and white matter pathology in schizophrenia: systematic review. Schizophr Res. 2015;161(1):102-12. https:// doi.org/10.1016/j.schres.2014.04.041.

32. Chew L-J, Fusar-Poli P, Schmitz T. Oligodendroglial alterations and the role of microglia in white matter injury: relevance to schizophrenia. Dev Neurosci. 2013;35(2-3):102-29. https://doi.org/10.1159/000346157.

33. Fillman SG, Cloonan N, Catts VS, Miller LC, Wong J, McCrossin T, et al. Increased inflammatory markers identified in the dorsolateral prefrontal cortex of individuals with schizophrenia. Mol Psychiatry. 2013;18(2):206-14. https://doi.org/10.1038/mp.2012.110.

34. Giridharan W, Scaini G, Colpo GD, Doifode T, Pinjari OF, Teixeira AL, et al. Clozapine Prevents Poly (l:C) Induced Inflammation by Modulating NLRP3 Pathway in Microglial Cells. Cells. 2020;9(3). https:/doi.org/10.3390/cells9030577.

35. Crocker CE, Tibbo PG. Confused connections? Targeting White Matter to Address Treatment Resistant Schizophrenia. Front Pharmacol. 2018:9:1172. https://doi.org/10.3389/fphar.2018.01417.

36. O'Sullivan D, Green L, Stone S, Zareie P, Kharkrang M, Fong D, et al. Treatment with the antipsychotic agent, risperidone, reduces disease severity in experimental autoimmune encephalomyelitis. PLoS One. 2014; 9(8):e104430. https://doi.org/10.1371/journal.pone.0104430.

37. Chandran P, Upadhyay J, Markosyan S, Lisowski A, Buck W, Chin CL, et al. Magnetic resonance imaging and histological evidence for the blockade of cuprizone-induced demyelination in C57BL/6 mice. Neuroscience. 2012;202: 446-53. https://doi.org/10.1016/j.neuroscience.2011.10.051.

38. Zhang $Y$, Zhang $H$, Wang $L$, Jiang $W, X u H$, Xiao $L$, et al. Quetiapine enhances oligodendrocyte regeneration and myelin repair after cuprizoneinduced demyelination. Schizophr Res. 2012;138(1):8-17. https://doi.org/10.1 016/j.schres.2012.04.006.

39. Vernon AC, Natesan S, Modo M, Kapur S. Effect of chronic antipsychotic treatment on brain structure: a serial magnetic resonance imaging study with ex vivo and postmortem confirmation. Biol Psychiatry. 2011;69(10):93644. https://doi.org/10.1016/j.biopsych.2010.11.010.

40. Bartzokis G. Neuroglialpharmacology: myelination as a shared mechanism of action of psychotropic treatments. Neuropharmacology. 2012;62(7):2137-53. https://doi.org/10.1016/..neuropharm.2012.01.015.

41. Feng Y. Convergence and divergence in the etiology of myelin impairment in psychiatric disorders and drug addiction. Neurochem Res. 2008;33(10): 1940-9. https://doi.org/10.1007/s11064-008-9693-x.

42. Bartzokis G, Lu PH, Amar CP, Raven EP, Detore NR, Altshuler LL, et al. Long acting injection versus oral risperidone in first-episode schizophrenia: differential impact on white matter myelination trajectory. Schizophr Res. 2011;132(1):35-41. https://doi.org/10.1016/j.schres.2011.06.029.

43. Bartzokis G, Lu PH, Nuechterlein KH, Gitlin M, Doi C, Edwards N, et al. Differential effects of typical and atypical antipsychotics on brain myelination in schizophrenia. Schizophr Res. 2007;93(1-3):13-22. https://doi. org/10.1016/j.schres.2007.02.011.

44. Lope-Piedrafita S. Diffusion Tensor Imaging (DTI). Methods Mol Biol (Clifton, NJ). 2018:1718:103-16

\section{Publisher's Note}

Springer Nature remains neutral with regard to jurisdictional claims in published maps and institutional affiliations.
Ready to submit your research? Choose BMC and benefit from:

- fast, convenient online submission

- thorough peer review by experienced researchers in your field

- rapid publication on acceptance

- support for research data, including large and complex data types

- gold Open Access which fosters wider collaboration and increased citations

- maximum visibility for your research: over $100 \mathrm{M}$ website views per year

At $\mathrm{BMC}$, research is always in progress.

Learn more biomedcentral.com/submissions 